\title{
Acute epiglottitis complicating an emphysematous abscess
}

\author{
Hung-Wen Chang, MD*; Wen-Jiun Lin, $\mathrm{MD}^{\dagger}$; Sung-Yuan $\mathrm{Hu}, \mathrm{MD}^{\ddagger \S \|}$
}

\begin{abstract}
A 32-year-old man presented to the emergency department with a 2-day history of nonproductive cough, fever, severe sore throat, odynophagia, and dysphagia. A chest radiograph showed no significant finding, but the lateral view of the neck demonstrated "vallecula" and "thumbprint" signs (Figure 1). Significant laboratory findings were a white blood cell count of $22,000 / \mu \mathrm{L}$ with 93\% neurtrophils and an elevated C-reactive protein at $51.6 \mathrm{mg} / \mathrm{L}(49.1 \mathrm{nmol} / \mathrm{L})$. Direct laryngoscopy revealed a swollen epiglottis (Figure 2). The neck computed tomographic (CT) scan demonstrated a swollen epiglottis with air bubbles in the heterogeneous lesion consistent with acute epiglottitis complicated by an emphysematous abscess (Figure 3).

Acute epiglottitis is a bacterial or viral infection of the supraglottic structures that can lead to upper airway obstruction, although this is rare in adult cases. $^{1-5}$ Clinical manifestations include fever, sore throat, muffled voice, dysphagia, odynophagia, drooling, dyspnea, and stridor. ${ }^{1-7}$ Emphysematous abscess is rare, with an incidence of 0 to $3 \%{ }^{1,6}$ Vallecula and thumbprint signs on the lateral view of the neck should aid in diagnosing acute epiglottitis. CT can assess the extent of the disease and identify possible complications. Direct laryngoscopy will show the adjacent structures of epiglottis. The most common pathogen is Haemophilus influenzae type B in children and Streptococcus pneumoniae in adults, but positive rates of throat swab and blood cultures are uncommon. ${ }^{1-7}$

Although radiologic studies demonstrated an emphysematous abscess in this patient, medical treatment was
\end{abstract}

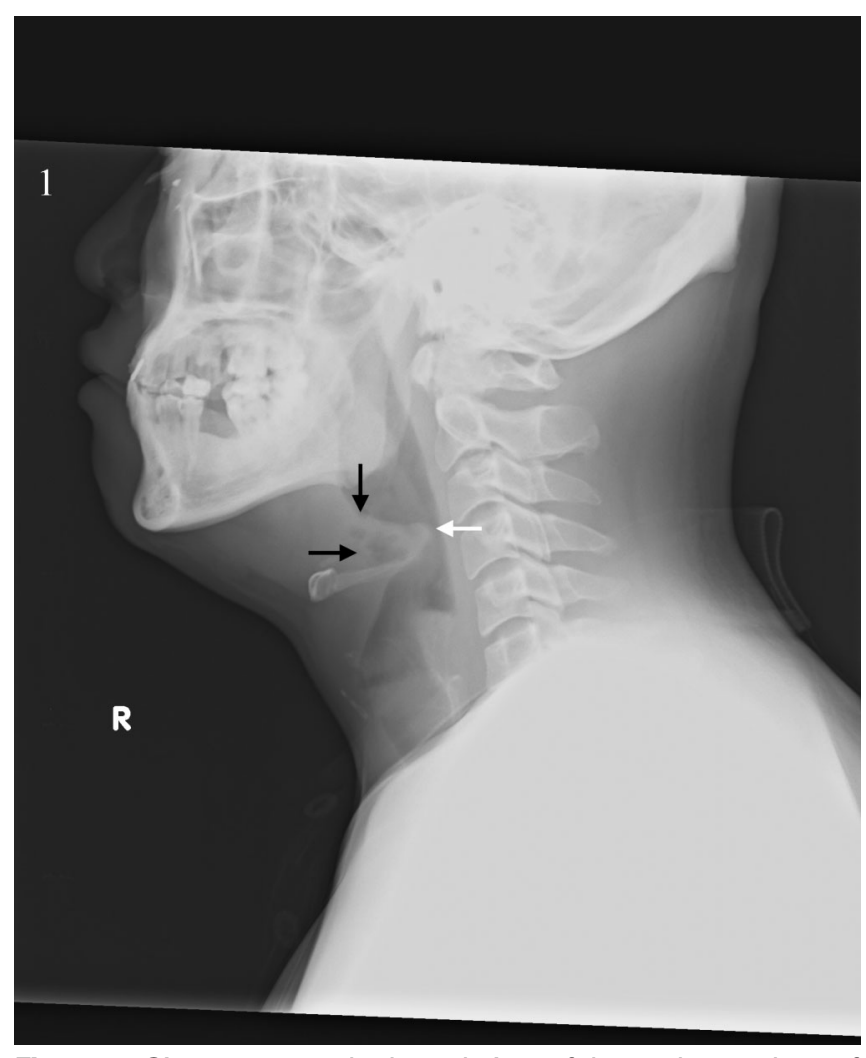

Figure 1. Signs seen on the lateral view of the neck were loss of the fold between the tongue base and epiglottis (vertical black arrow) and air bubbles (horizontal black arrow) superimposed on a rounded configuration of the epiglottis (horizontal white arrow).

initiated without intubation because there were no signs of respiratory distress.

Competing interests: None declared.

Keywords: acute epiglottitis, computed tomography, emphysematous abscess

\footnotetext{
From the *Department of Emergency Medicine, Dajia Lee's General Hospital, Lee's Medical Corporation; Departments of †Otolaryngology and ‡Emergency Medicine, Taichung Veterans General Hospital; §Institute of Medicine, \|School of Medicine, Chung Shan Medical University; and -Department of Nursing, National Taichung University of Science and Technology, Taichung, Taiwan, Republic of China.
}

Correspondence to: Dr. Sung-Yuan Hu, No. 160, Sec. 3, Chung-Kang Road, Taichung, Taiwan, Republic of China 00407; song9168@pie.com.tw. This article has been peer reviewed. 

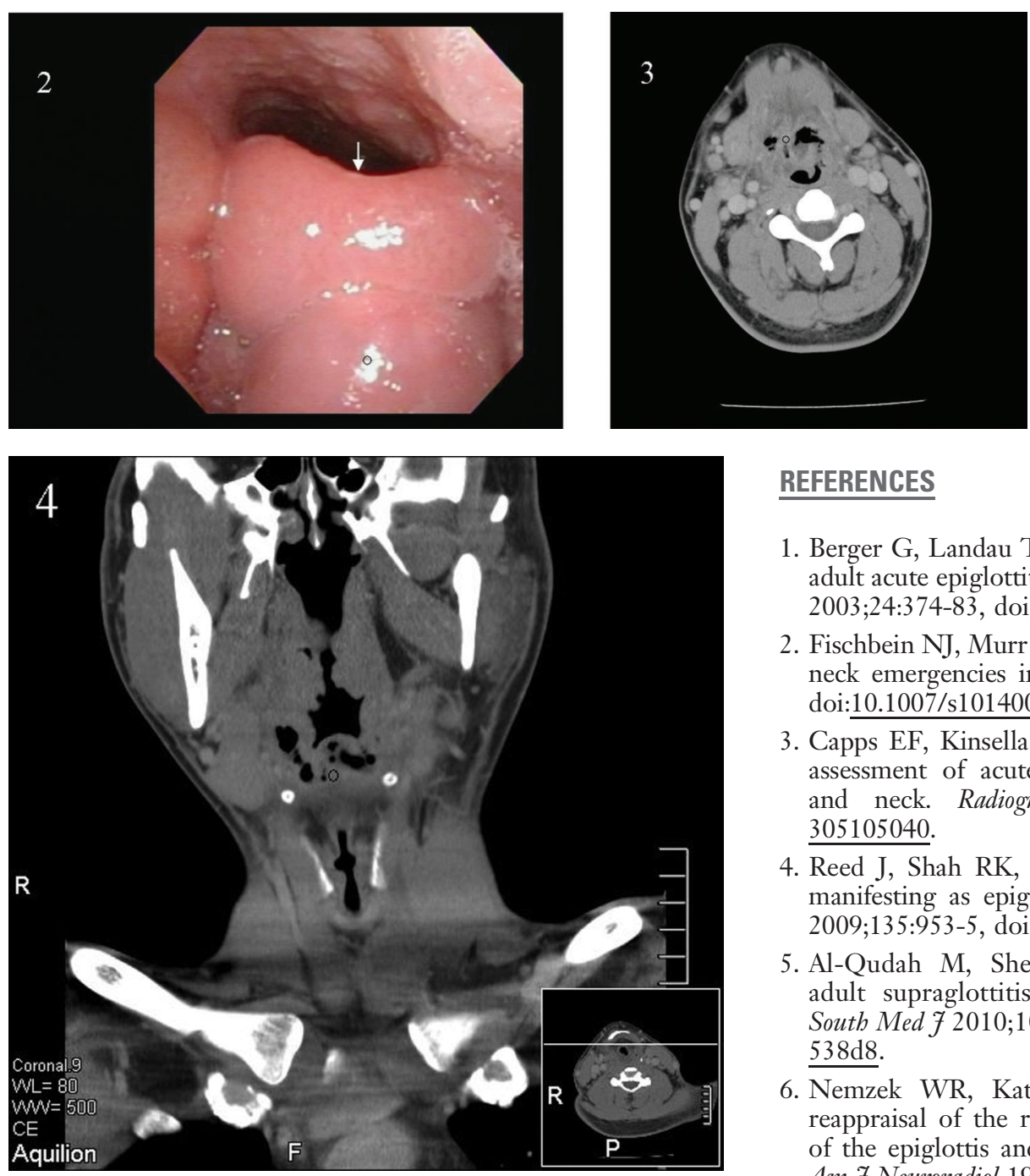

Figure 3. The axial view of the neck computed tomographic scan depicted a swollen epiglottis with air bubbles in the heterogeneous lesion (black hollow circle) consistent with acute emphysematous epiglottitis.

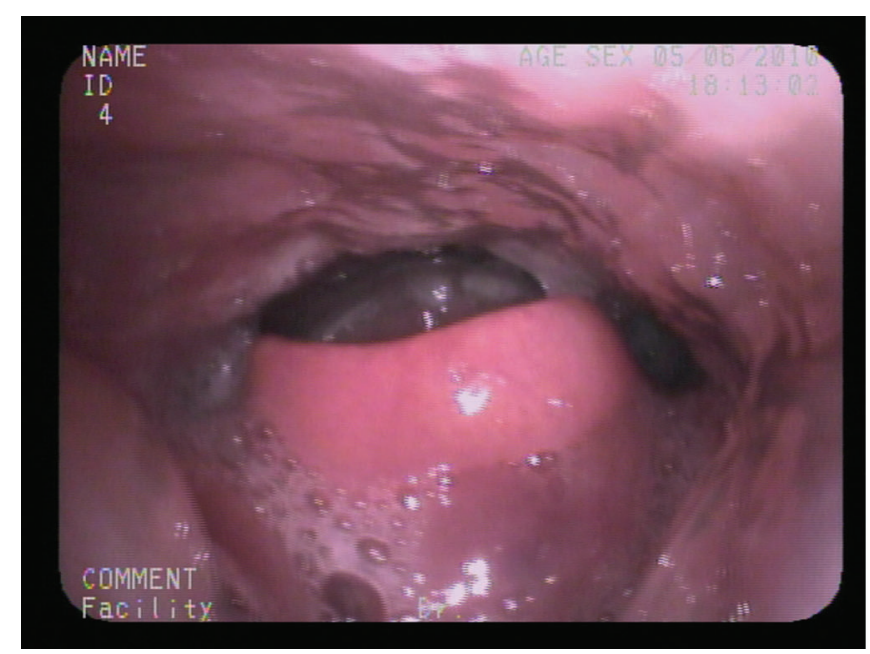

\section{REFERENCES}

1. Berger G, Landau T, Berger S, et al. The rising incidence of adult acute epiglottitis and epiglottic abscess. Am 7 Otolaryngol 2003;24:374-83, doi:10.1016/S0196-0709(03)00083-8.

2. Fischbein NJ, Murr AH. Imaging traumatic and nontraumatic neck emergencies in the adult. Emerg Radiol 1999;6:94-109, doi:10.1007/s101400050033.

3. Capps EF, Kinsella JJ, Gupta M, et al. Emergency imaging assessment of acute, nontraumatic conditions of the head and neck. Radiographics 2010;30:1335-2, doi:10.1148/rg. 305105040.

4. Reed J, Shah RK, Jantausch B, et al. Aryepiglottic abscess manifesting as epiglottitis. Arch Otolaryngol Head Neck Surg 2009;135:953-5, doi:10.1001/archoto.2009.116.

5. Al-Qudah M, Shetty S, Alomari M, Alqdah M. Acute adult supraglottitis: current management and treatment. South Med F 2010;103:800-4, doi:10.1097/SMJ.0b013e3181e $\underline{538 \mathrm{~d} 8}$.

6. Nemzek WR, Katzberg RW, Van Slyke MA, et al. A reappraisal of the radiologic findings of acute inflammation of the epiglottis and supraglottic structures in adults. A7NR Am 7 Neuroradiol 1995;16:495-502.

7. Price IM, Preyra I, Fernandes CM, et al. Adult epiglottitis: a five-year retrospective chart review in a major urban centre. CFEM 2005;7:387-90.

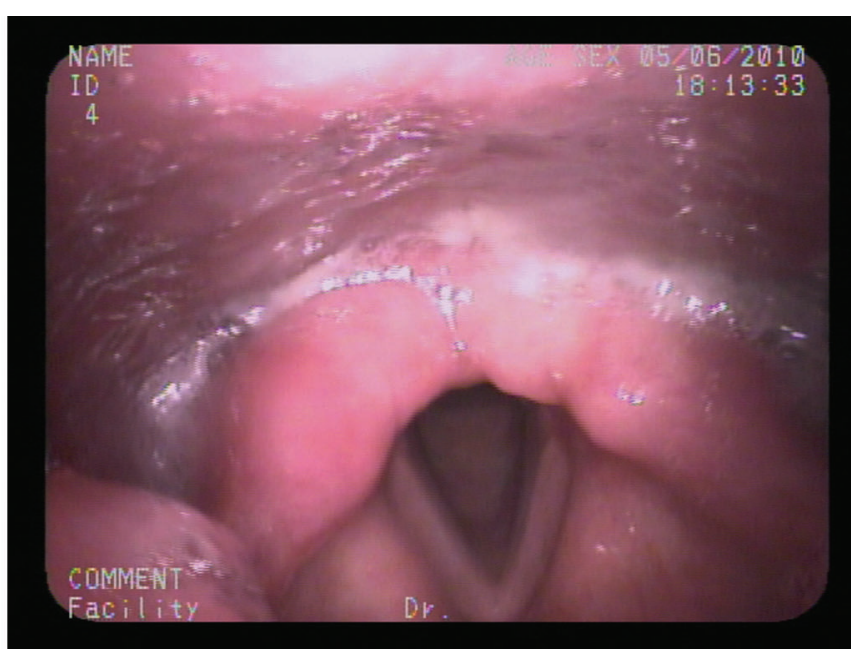

Figure S1. Direct laryngoscopy demonstrated a significant reduction in the swelling of the epiglottis and visible vocal cords after treatment with antibiotics and dexamethasone for 3 days. 